\title{
Influence of milling media on the physicochemicals and catalytic properties of mechanochemical treated vanadium phosphate catalysts.
}

\begin{abstract}
VOHPO $4 \cdot 0.5 \mathrm{H} 2 \mathrm{O}$ synthesized via the alcohol reduction of VOPO $4 \cdot 2 \mathrm{H} 2 \mathrm{O}$ was mechanochemical treated for $30 \mathrm{~min}$ in three different media, i.e. cyclohexane, ethanol and air. XRD results revealed that their structure became less crystalline compared to the unmilled material. SEM showed that the particles for the milled materials become smaller and unique features were observed in the different type of media used. The reactivity of the oxygen species linked to $\mathrm{V} 5+$ and $\mathrm{V} 4+$ were also affected by the milling process. The selectivity to maleic anhydride from n-butane oxidation were observed to increase in line with the increase in the oxygen species associated with V 5+ and the presence of isolated V $5+$ phase. A correlation was observed between the crystallite size of the pyrophosphate phase at (020) plane with the maleic anhydride selectivity.
\end{abstract}

Keyword: Mechanochemical; Vanadium phosphate; Maleic anhydride; N-butane oxidation. 